\title{
Methods of suicide predict the risks and method-switching of subsequent suicide attempts: a community cohort study in Taiwan
}

This article was published in the following Dove Press journal:

Neuropsychiatric Disease and Treatment

5 May 2014

Number of times this article has been viewed

\author{
Yu-Chi Huang' \\ Ya-Wen Wu ${ }^{2}$ \\ Chih-Ken Chen ${ }^{3}$ \\ Liang-Jen Wang ${ }^{4}$ \\ 'Department of Psychiatry, Kaohsiung \\ Chang Gung Memorial Hospital and \\ Chang Gung University College \\ of Medicine, Kaohsiung, Taiwan; \\ ${ }^{2}$ Department of Psychiatry, Chang \\ Gung Memorial Hospital, Keelung, \\ Taiwan; ${ }^{3}$ Department of Psychiatry, \\ Chang Gung Memorial Hospital, \\ Keelung and Chang Gung University \\ School of Medicine, Taoyuan, Taiwan; \\ ${ }^{4}$ Department of Child and Adolescent \\ Psychiatry, Kaohsiung Chang Gung \\ Memorial Hospital and Chang Gung \\ University College of Medicine, \\ Kaohsiung, Taiwan
}

Objective: Suicide is a major public health concern. This study aimed to determine the predictors of repeated suicide attempts, focusing on whether lethality level of the suicidal method predicts the risk of subsequent suicide attempts.

Methods: All consecutive individuals $(\mathrm{N}=2,070)$ with an episode of nonfatal self-harm registered in a surveillance database provided by the Department of Health of Keelung City Government in Taiwan from January 1, 2006 to December 31, 2010 were enrolled and followed up until the end of 2011. The earliest attempt recorded in the database was defined as the index attempt. Subjects were classified according to suicide method into low-lethal and high-lethal groups. Data on time of and methods chosen for subsequent suicide attempts during the follow-up period were analyzed.

Results: Of the total people screened for the study, 18.1\% made a repeated suicide attempt. Subjects in the high-lethal group were more likely to be male; aged 35-64 years; and single, divorced, or widowed. Compared to other time intervals, most subsequent suicide attempts occurred within 6 months from the index attempt. The independent predictors for repeated suicide attempts were the use of low-lethal methods in the index attempt and being 35-49 years old. Using high-lethal methods and being older than 50 years were associated with changing suicide method for the second attempt.

Conclusion: Lethality level of former suicidal method could predict repeated suicide attempts and changing of suicide methods. Further clarification is needed on whether a higher risk of repeat attempts is associated with higher rates of suicide mortality.

Keywords: lethality, method of suicide, suicide repetition, risk factor, survival analysis

\section{Introduction}

Suicide remains a major public health issue, not only because of the estimated 1 million worldwide deaths by suicide every year, ${ }^{1}$ but also because of its increasing contribution to the universal burden of disease - from 1.8\% in 1998 to an estimated more than $2 \%$ by $2020 .^{2}$ Over the past 2 decades, suicide has become the ninth leading cause of death in Taiwan, with a more than threefold increase in suicide rate being reported.,4 Investigations of suicidal behavior and early recognition of high-risk groups are important for suicide prevention. ${ }^{5}$

Among the risk factors of suicide, a former suicide attempt is one of the strongest predictors of future attempts. ${ }^{6-9}$ About one-half to two-thirds of people who attempt suicide are documented to have made a previous attempt. ${ }^{10}$ A reported $16 \%$ of people attended the emergency room after a suicide attempt and $1.3 \%$ eventually died. ${ }^{11}$ Nevertheless, nearly half of the people who present to a hospital's accident and
Correspondence: Liang-Jen Wang Department of Child and Adolescent Psychiatry, Kaohsiung Chang Gung Memorial Hospital I23, Ta-Pei Road, Niao-Sung District, Kaohsiung City 8330I, Taiwan

$\mathrm{Tel}+8867731 \quad 7123$ ext 6319

Fax +8867732 6817

Email wangliangjen@gmail.com 
emergency department after a suicide attempt have no comprehensive assessment. ${ }^{12,13}$ As a consequence, it is important to identify groups at high risk of repeated attempts, regardless of ethical, medical, or cost considerations. ${ }^{14}$

A number of studies have focused on the socioepidemiology and psychopathology of repeated suicide attempts. ${ }^{15-17}$ Their results suggested that young age, female sex, low socioeconomic status, low education, being divorced, living alone or alone with a child, and high severity of psychiatric symptoms were associated with repeated suicide attempts. ${ }^{18,19}$ Furthermore, the method used during the first suicide attempt has been demonstrated to serve as an important predictor of completed subsequent attempts. ${ }^{20,21}$ Methods of suicide have been classified as low-lethal and high-lethal. ${ }^{22}$ Higher rates of suicide death are related to high-lethal suicide attempts, such as firearms and hanging, in Western countries, and charcoal burning or pesticides ingestion in Eastern countries. ${ }^{23,24} \mathrm{By}$ contrast, poisoning and self-injuries with sharp instruments are generally identified as low-lethal methods. ${ }^{20}$ In addition, changing the method of subsequent suicide attempts may lead to a greater likelihood of suicide mortality. ${ }^{25}$ However, few studies have explored how the initial method chosen influences future attempts.

Therefore, the aim of this study was to determine the predictors of repeated suicide attempts, with particular focus on whether the initial level of lethality chosen predicts the risk of subsequent attempts. We also investigated whether people who tried to reattempt suicide switch methods during subsequent suicide attempts and the factors associated with switching approaches.

\section{Methods}

\section{Study sample and data collection}

The study received approval from the Institutional Review Board of the Chang Gung Memorial Hospital. This study enrolled all consecutive individuals with an episode of nonfatal self-harm registered in a surveillance database provided by the Department of Health of Keelung City Government from January 1, 2006 to December 31, 2010. Keelung City, which has approximately 0.4 million inhabitants, had the highest suicide mortality rate in Taiwan from 2002 to 2011 (the average suicide mortality rate per 100,000 people was 25.1). In collaboration with the local health authority, the Suicide Prevention Center was established in Keelung City in 2005 to compile a surveillance database and offer suicide prevention programs. Under this system, once a staff member in the health sectors (emergency departments at hospitals and general practice and local public health centers) notices any person presenting evidence of self-harm, a structured casenotes form is used to record the individual's basic information and method of suicide attempt. Suicide attempt is defined as any potentially life-threatening act of self-harm requiring treatment. All of the health sectors are required to complete and submit the written form and fax it to the Suicide Prevention Center of Keelung City after each attempt. The surveillance database is in electronic format, and the demographic variables consist of sex, dates of birth and death, marital status, education levels, and method of suicide.

During the enrollment period, 2,070 individuals qualified for analysis in this study. If a participant had more than one suicide attempt during the study period, the earliest attempt recorded in the database was considered the index attempt. Follow-up was then carried out to the end of 2011, and all individuals were followed for at least 1 year. The Department of Health of Keelung City Government also collected the data on any subsequent suicide attempts after the index attempt. Of the sample, 374 (18.1\%) made at least one other attempt at suicide during the follow-up period.

\section{Identification of suicide method}

Suicide methods were classified using the codes of the International Classification of Diseases, Ninth Revision, Clinical Modification (ICD-9-CM). Following previous epidemiology research, ${ }^{20,22,26}$ individuals who attempted suicide were classified into two groups based on the lethality of their suicide method. The first, the low-lethal group, consisted of those who attempted suicide through poisoning by solid or liquid substances (E950) or used cutting and piercing instruments (E956). The second, the high-lethal group, consisted of those who attempted suicide through poisoning by domestically used gas (E951), poisoning by other gases and vapors (E952), hanging (E953), drowning (E954), firearms, air guns and explosives (E955), jumping from high places (E957), and other unspecified means (E958). Most of the individuals $(\mathrm{N}=1,935)$ used a single method at the index attempt, while 133 people used two distinct methods (most common combination was drug overdose plus self-cutting $[\mathrm{n}=79,59.4 \%]$, followed by drug overdose plus charcoal burning $[\mathrm{n}=30,22.6 \%]$ ), and two people used three different strategies. The main technique used in the index attempt was defined as the most lethal by clinical judgment when an individual used more than one method.

\section{Statistical analysis}

Data were analyzed using the statistical software package SPSS (v 16.0; SPSS Inc., Chicago, IL, USA). Individuals 
were classified into two groups, low-lethality and highlethality, based on the methods used in their index suicide attempt. Variables are presented as either the mean (standard deviation) or frequency. A chi-square $\left(\chi^{2}\right)$ test was used to compare variables between the low-lethality group and the high-lethality group.

Each person's first presentation within the study period was used in the calculation of risk over time. All individuals tracked until December 31, 2011 for any length of time from their index attempt were entered into a survival analysis. The hazard ratios (with a 6-month interval) of subsequent suicide attempt during the follow-up period were calculated using life tables. The Wilcoxon signed-rank test was used to compare the hazard ratios between groups by the methods of the index suicide attempt. In the survival analysis, the time function was calculated as the number of months from the index suicide attempt to December 2011 (end of follow-up) for those who made no further attempts up to that point or until the date of another suicide attempt if it preceded the end of the follow-up interval. Cumulative survival rates during the follow-up period were expressed by survival curves. Cox regression models were fitted to estimate the effects of suicide methods in the index episode, controlling for sex, age, marital status, and education levels. Unadjusted hazard ratios (HRs) and adjusted HRs with 95\% confidence intervals were calculated.

For those people who made another suicide attempt, we further analyzed the distribution of individuals who changed the suicide method and who maintained the same method in their second attempt. McNemar's test was applied to compare the methods chosen in the index attempt and in the second attempt. Logistic regression analysis was used to examine the effect of variables (ie, sex, age, marital status, education level, and lethality of suicide method) on changing methods of suicide. Unadjusted odds ratios (ORs) and adjusted ORs with $95 \%$ confidence intervals were calculated. Two-tailed $P$-values of less than 0.05 were considered statistically significant.

\section{Results}

This study enrolled 2,070 individuals (mean age: $40.5 \pm 15.6$ years) with a nonfatal index suicide attempt registered between 2006 and 2010. Of these, 1,394 (67.3\%) were women and $676(32.7 \%)$ were men; 538 (26.0\%) individuals were single, 786 (38.0\%) were married, and 732 (35.4\%) were divorced or widowed; 764 (36.9\%) individuals had a junior high school education or lower, and 1,306 (63.1\%) had an education level of high school or above. There were
$374(18.1 \%)$ people who made a repeat suicide attempt by the end of the follow-up period. Of the total participants, $1,730(83.6 \%)$ individuals used a low-lethal method and 340 (16.4\%) used a high-lethal method in their index attempt. Compared with the low-lethal group (Table 1), the high-lethal group were significantly more likely to be male $\left(\chi^{2}=57.54\right.$, $P<0.001)$; to be between 35 and 64 years old $\left(\chi^{2}=15.13\right.$, $P=0.002)$; and to be single, divorced, or widowed $\left(\chi^{2}=12.60\right.$, $P=0.002)$, and were significantly less likely to make a repeat attempt $\left(\chi^{2}=9.92, P=0.002\right)$.

Of the total sample, more subsequent suicide attempts $(n=149,39.8 \%)$ occurred within 6 months after the index attempt than in any other time interval. The cumulative proportion of individuals who survived a repeated suicide attempt was $76.4 \%$ at the end of the follow-up. For the analysis segregated by method group (Table 2), the hazard ratios of subsequent suicide attempt within 6 months were the highest throughout the study period in both the low-lethal group $(n=135,40.5 \%)$ and the high-lethal group $(n=14$, $34.1 \%$ ). The cumulative proportion of individuals who survived a follow-up attempt in the low-lethal group and in the high-lethal group was $75.2 \%$ and $82.8 \%$, respectively. There was a significant difference in hazard rates between the low-lethal and high-lethal groups (Wilcoxon statistic: 8.20, $P=0.004)$.

In unadjusted Cox regression analyses (Table 3), subsequent suicide attempts were more likely to have occurred among women $(\mathrm{HR}=1.32, P=0.014)$ and individuals aged between 35 and 49 years $(\mathrm{HR}=1.38, P=0.005)$. Repeated attempts were less likely to occur among individuals older than 65 years $(\mathrm{HR}=0.58, P=0.032)$ and if the person used a high-lethal method during the index attempt $(\mathrm{HR}=0.63$, $P=0.006$ ). In adjusted Cox proportional hazard modeling, the independent predictors were being between 35 and 49 years (HR $=1.48, P=0.003)$ and the use of high-lethal methods in the index attempt $(\mathrm{HR}=0.62, P=0.005)$.

Of the 374 individuals who made a repeated suicide attempt, 71 (19.0\%) switched their suicide method to one classified at a different lethality level $(P<0.001)$. Of the people who used low-lethal methods in the index attempt, $56(16.8 \%)$ changed to high-lethal methods for the second suicide attempt. In contrast, of those who used high-lethal methods in the index attempt, $15(36.6 \%)$ switched to lowlethal methods for their second attempt. Unadjusted logistic regression analyses (Table 4 ) showed that individuals older than 65 years $(\mathrm{OR}=3.33, P=0.025)$ and people who used high-lethal methods in the index attempt $(\mathrm{OR}=2.85, P=0.003)$ tended to change suicide method in their second attempts. 
Table I Characteristics of survivors of nonfatal suicide attempts, by low-lethality methods and by high-lethality methods, in Keelung City, Taiwan, from 2006 to 2010

\begin{tabular}{|c|c|c|c|c|}
\hline Characteristics & $\begin{array}{l}\text { Total }(\mathbf{N}=2,070) \\
N(\%)\end{array}$ & $\begin{array}{l}\text { Low-lethality }^{a}(\mathrm{~N}=\mathrm{I}, 730) \\
\mathbf{N}(\%)\end{array}$ & $\begin{array}{l}\text { High-lethality }{ }^{\mathrm{b}}(\mathrm{N}=340) \\
\mathrm{N}(\%)\end{array}$ & Significance \\
\hline Sex & & & & $\chi^{2}=57.54, d f=I, P<0.00 I * * *$ \\
\hline Female & $1,394(67.3)$ & $\mathrm{I}, 225(70.8)$ & $169(49.7)$ & \\
\hline Male & $676(32.7)$ & $505(29.2)$ & $17 \mid(50.3)$ & \\
\hline Age at the index attempt ${ }^{c}$ (years) & & & & $\chi^{2}=15.13, d f=3, P=0.002^{* *}$ \\
\hline$<35$ & $826(39.9)$ & $7 \mid 5(4 \mid .3)$ & III (32.6) & \\
\hline $35-49$ & $738(35.7)$ & $589(34.0)$ & $149(43.8)$ & \\
\hline $50-64$ & $324(15.7)$ & $267(15.4)$ & $57(16.8)$ & \\
\hline$>64$ & I8I (8.7) & $158(9.1)$ & $23(6.8)$ & \\
\hline Not available & $\mathrm{I}(<0 . \mathrm{I})$ & $\mathrm{I}(0 . \mathrm{I})$ & $0(0)$ & \\
\hline Marital status & & & & $\chi^{2}=12.60, d f=2, P=0.002^{* *}$ \\
\hline Single & $538(26.0)$ & $446(25.8)$ & $92(27.1)$ & \\
\hline Married & $786(38.0)$ & $684(39.5)$ & $102(30.0)$ & \\
\hline Divorced or widowed & $732(35.4)$ & $588(34.0)$ & $144(42.4)$ & \\
\hline Not available & $14(0.7)$ & $12(0.7)$ & $2(0.6)$ & \\
\hline Amount of education (years) & & & & $\chi^{2}=0.31, d f=I, P=0.579$ \\
\hline$\leq 9$ & $764(36.9)$ & $634(36.6)$ & $130(38.2)$ & \\
\hline$>9$ & $1,306(63.1)$ & $\mathrm{I}, 096(63.4)$ & $210(61.8)$ & \\
\hline Subsequent suicide attempt & & & & $\chi^{2}=9.92, d f=I, P=0.002 * *$ \\
\hline No & $1,696(81.9)$ & I,397 (80.8) & $299(87.9)$ & \\
\hline Yes & $374(18.1)$ & $333(19.2)$ & $41(12.1)$ & \\
\hline
\end{tabular}

Notes: ancluding drug overdose and self-cutting; 'including charcoal burning, hanging, jumping from high places, drowning, poisoning by domestically used gas, and other methods; cthe earliest suicide attempt recorded in the database. $* * P<0.01$; $* * * P<0.001$.

Women were less likely to change suicide method $(\mathrm{OR}=0.49, \quad$ Discussion

$P=0.010$ ). Adjusted logistic regression modeling showed that the independent predictors of changing suicide method were being between 50 and 64 years $(\mathrm{OR}=2.50, P=0.047)$, being older than 65 years $(\mathrm{OR}=3.77, P=0.045)$, and the use of high-lethal method in the index attempt $(\mathrm{OR}=2.64$, $P=0.010$ ).
During the follow-up period of this study, $18.1 \%$ of the sample made a repeated suicide attempt. This finding is consistent with another study in which $15 \%-16 \%$ of non-lethal outcomes were followed by a repeated attempt of suicide and $2 \%$ completed suicide 1 year after the study was concluded. ${ }^{11}$ It has also been reported that a diverse range of non-lethal

Table 2 Hazard ratios of subsequent suicide attempts $(\mathrm{N}=374)$ after the index attemptc ${ }^{\mathrm{c}}$, by different methods, followed to the end of 2011

\begin{tabular}{|c|c|c|c|c|c|c|c|c|c|}
\hline \multirow{2}{*}{$\begin{array}{l}\text { Time } \\
\text { (months) }\end{array}$} & \multicolumn{3}{|l|}{ Total } & \multicolumn{3}{|c|}{ Low-lethal group ${ }^{a}$} & \multicolumn{3}{|c|}{ High-lethal group } \\
\hline & $\begin{array}{l}\text { Number of } \\
\text { terminal } \\
\text { events }\end{array}$ & $\begin{array}{l}\text { Number } \\
\text { of patients }\end{array}$ & $\begin{array}{l}\text { Hazard } \\
\text { ratio }\left(10^{-3}\right)\end{array}$ & $\begin{array}{l}\text { Number of } \\
\text { terminal } \\
\text { events }\end{array}$ & $\begin{array}{l}\text { Number } \\
\text { exposed } \\
\text { to risk }\end{array}$ & $\begin{array}{l}\text { Hazard } \\
\text { ratio }\left(10^{-3}\right)\end{array}$ & $\begin{array}{l}\text { Number of } \\
\text { terminal } \\
\text { events }\end{array}$ & $\begin{array}{l}\text { Number } \\
\text { exposed } \\
\text { to risk }\end{array}$ & $\begin{array}{l}\text { Hazard } \\
\text { ratio }\left(10^{-3}\right)\end{array}$ \\
\hline $0-6$ & 149 & $2,061.5$ & 12.50 & 135 & $\mathrm{I}, 725$ & 13.57 & 14 & 336.5 & 7.08 \\
\hline $7-12$ & 55 & 1,904 & 4.88 & 50 & I,585 & 5.34 & 5 & 319 & 2.63 \\
\hline $13-18$ & 48 & $1,769.5$ & 4.58 & 41 & $|, 47|$ & 4.71 & 7 & 298.5 & 3.95 \\
\hline $19-24$ & 27 & $\mathrm{I}, 557$ & 2.92 & 23 & 1,300 & 2.98 & 4 & 257 & 2.61 \\
\hline $25-30$ & 21 & I,370.5 & 2.57 & 19 & 1,156 & 2.76 & 2 & 214.5 & 1.56 \\
\hline $31-36$ & 22 & $\mathrm{I}, 202.5$ & 3.08 & 19 & $\mathrm{I}, 024$ & 3.12 & 3 & 178.5 & 2.82 \\
\hline $37-42$ & 17 & $\mathrm{I}, 0 \mid 4.5$ & 2.82 & 14 & 866 & 2.72 & 3 & 148.5 & 3.40 \\
\hline $43-48$ & 12 & 839 & 2.40 & 11 & 715.5 & 2.58 & I & 123.5 & 1.36 \\
\hline $49-54$ & 6 & 675 & 1.49 & 5 & 572.5 & 1.46 & I & 102.5 & 1.63 \\
\hline $55-60$ & 10 & 485.5 & 3.47 & 10 & 412 & 4.10 & 0 & 73.5 & 0 \\
\hline $6 I-66$ & 7 & 279.5 & 4.23 & 6 & 240.5 & 4.21 & I & 39 & 4.33 \\
\hline $67-72$ & 0 & 86.5 & 0 & 0 & 76 & 0 & 0 & 10.5 & 0 \\
\hline
\end{tabular}

Notes: ancluding those who attempted suicide through drug overdose and self-cutting; bincluding those who attempted suicide through charcoal burning, hanging, jumping from high places, drowning, domestically used gases, and other methods; 'the earliest suicide attempt recorded in the database. 
Table 3 HRs of subsequent suicide attempts $(n=374)$ after the index attempt ${ }^{d}$ for related variables by Cox proportional hazards modeling

\begin{tabular}{|c|c|c|c|c|c|}
\hline \multirow[t]{2}{*}{ Variables } & \multirow{2}{*}{$\begin{array}{l}\text { Subsequent suicide } \\
\text { attempts }^{\mathrm{a}} \\
\mathrm{n} / \mathrm{N}(\%)\end{array}$} & \multicolumn{2}{|l|}{ Unadjusted HR } & \multicolumn{2}{|l|}{ Adjusted HR } \\
\hline & & HR (95\% Cl) & $P$-value & HR (95\% CI) & $P$-value \\
\hline \multicolumn{6}{|l|}{ Sex } \\
\hline Male & $101 / 676(14.9)$ & 1 & & 1 & \\
\hline Female & $273 / 1,394(19.6)$ & $1.32(1.05-1.66)$ & $0.014^{*}$ & $1.26(0.99-1.59)$ & 0.059 \\
\hline \multicolumn{6}{|l|}{ Age (years) } \\
\hline$<35$ & $137 / 826(16.6)$ & 1 & & I & \\
\hline $35-49$ & I64/738 (22.2) & $1.38(1.10-1.74)$ & $0.005^{* *}$ & $1.48(1.15-1.91)$ & $0.003^{* *}$ \\
\hline $50-64$ & $55 / 324(17.0)$ & $1.07(0.78-1.46)$ & 0.688 & $1.19(0.83-1.69)$ & 0.347 \\
\hline$>64$ & $18 / 18 \mid(9.9)$ & $0.58(0.36-0.95)$ & $0.032 *$ & $0.65(0.38-1.12)$ & 0.118 \\
\hline \multicolumn{6}{|l|}{ Marital status } \\
\hline Single & $94 / 538(17.5)$ & 1 & & 1 & \\
\hline Married & $126 / 786(16.0)$ & $0.91(0.69-1.18)$ & 0.486 & $0.80(0.60-1.08)$ & 0.143 \\
\hline Divorced or widowed & $|5| / 732(20.6)$ & $1.17(0.90-\mid .5 I)$ & 0.237 & $1.03(0.77-1.39)$ & 0.833 \\
\hline \multicolumn{6}{|c|}{ Amount of education (years) } \\
\hline$\leq 9$ & $126 / 764(16.5)$ & 1 & & 1 & \\
\hline$>9$ & $248 / 1,306(19.0)$ & $1.15(0.93-1.43)$ & 0.196 & $1.06(0.84-1.35)$ & 0.608 \\
\hline \multicolumn{6}{|c|}{ Method of the index attempt } \\
\hline Low-lethal ${ }^{b}$ & $333 / 1,730(19.2)$ & 1 & & 1 & \\
\hline High-lethal ${ }^{\mathrm{c}}$ & $41 / 340(12.1)$ & $0.63(0.46-0.88)$ & 0.006 ** & $0.62(0.45-0.86)$ & $0.005^{* *}$ \\
\hline
\end{tabular}

Notes: andividuals with missing data were excluded in the analyses; bincluding drug overdose and self-cutting; cincluding charcoal burning, hanging, jumping from high places, drowning, poisoning by domestically used gases, and other methods; ${ }^{d}$ the earliest suicide attempt recorded in the database. $* P<0.05$; $* * P<0.0$ I.

Abbreviations: $\mathrm{Cl}$, confidence interval; $\mathrm{HR}$, hazard ratio; $\mathrm{n}$, number of individuals who had a second suicide attempt; $\mathrm{N}$, number of total subjects.

suicide attempts after one index attempt is linked to a repeat suicide rate of up to $37 \%$ within 5 years of follow-up. ${ }^{27}$ It is noteworthy that $39.8 \%$ of subsequent suicide attempts tend to occur within 6 months after the index attempt. Similar to our findings, Cooper et al reported that the highest rate of repeated suicide attempts occurs within 6 months after the initial attempt is made. ${ }^{28}$ High rates of repeated attempts in the first 1-3 years after the index attempt have been observed in other studies. ${ }^{3,29}$ Moreover, the rate of repeated suicide attempts has been documented to remain high even

Table 4 ORs of changing methods of suicide $(n=7 I)$ in individuals who had a second suicide attempt after the index attempt ${ }^{c}(\mathrm{~N}=374)$ by logistic regression analysis

\begin{tabular}{|c|c|c|c|c|c|}
\hline \multirow[t]{2}{*}{ Variables } & \multirow{2}{*}{$\begin{array}{l}\text { Change of suicide method } \\
n / N(\%)\end{array}$} & \multicolumn{2}{|l|}{ Unadjusted OR } & \multicolumn{2}{|l|}{ Adjusted OR } \\
\hline & & OR $(95 \% \mathrm{Cl})$ & $P$-value & OR $(95 \% \mathrm{Cl})$ & $P$-value \\
\hline \multicolumn{6}{|l|}{ Sex } \\
\hline Male & 28/I0I (27.7) & I & & I & \\
\hline Female & $43 / 273(15.8)$ & $0.49(0.28-0.84)$ & $0.010 * *$ & $0.62(0.34-1.13)$ & 0.119 \\
\hline \multicolumn{6}{|l|}{ Age (years) } \\
\hline$<35$ & $22 / 137(16.1)$ & I & & 1 & \\
\hline $35-49$ & $27 / 164(16.5)$ & $1.03(0.56-1.91)$ & 0.924 & $0.96(0.45-2.06)$ & 0.921 \\
\hline $50-64$ & I5/55 (27.3) & $1.96(0.93-4.14)$ & 0.078 & $2.50(1.01-6.17)$ & $0.047^{*}$ \\
\hline$>64$ & $7 / 18(38.9)$ & $3.33(1.16-9.52)$ & $0.025^{*}$ & $3.77(1.03-13.80)$ & $0.045^{*}$ \\
\hline \multicolumn{6}{|l|}{ Marital status } \\
\hline Single & I7/94 (I8.I) & I & & 1 & \\
\hline Married & $17 / 126(13.5)$ & $0.7 I(0.34-1.47)$ & 0.353 & $0.64(0.26-1.54)$ & 0.318 \\
\hline Divorced or widowed & $37 / 151$ (24.5) & $1.47(0.77-2.80)$ & 0.240 & $1.42(0.64-3.16)$ & 0.393 \\
\hline \multicolumn{6}{|c|}{ Amount of education (years) } \\
\hline$\leq 9$ & $24 / 126(19.0)$ & I & & 1 & \\
\hline$>9$ & $47 / 248(19.0)$ & $0.99(0.58-1.72)$ & 0.982 & $1.30(0.68-2.50)$ & 0.433 \\
\hline \multicolumn{6}{|c|}{ Method of the index attempt } \\
\hline Low-lethal ${ }^{b}$ & $56 / 333(16.8)$ & 1 & & 1 & \\
\hline High-lethal ${ }^{c}$ & $|5 / 4|(36.6)$ & $2.85(1.42-5.73)$ & $0.003^{* *}$ & $2.64(1.26-5.55)$ & $0.010 *$ \\
\hline
\end{tabular}

Notes: andividuals with missing data were excluded in the analyses; 'including drug overdose and self-cutting; 'including charcoal burning, hanging, jumping from high places, drowning, poisoning by domestically used gases, and other methods; ' the earliest suicide attempt recorded in the database. $* P<0.05$; $* * P<0.01$.

Abbreviations: $\mathrm{Cl}$, confidence interval; $\mathrm{n}$, number of individuals who changed methods of suicide; $\mathrm{N}$, number of individuals who had a second suicide attempt; OR, odds ratio. 
16-37 years after the index attempt..$^{30,31}$ However, the findings in our study suggest that clinicians should carefully evaluate the risk of repeated suicide attempts among people who have a history of attempted suicide, especially within six months after their index attempt.

In this study, the lethality level of the method chosen for the index attempt was a significant predictor of subsequent attempts. Suicide methods are well established as an important item in clinical assessment for the seriousness of suicidal behavior. The choice of suicide method is potentially influenced by one's personal characteristics and sociocultural accessibility. ${ }^{24}$ However, the most important implication of the lethality of suicide method may represent the degree of intent of the person to complete suicide. ${ }^{32}$ Suicidal intent is recognized as the seriousness or intensity of one's wish to terminate one's own life. Individuals with high-lethal suicide attempts exhibit a lesser degree of help-seeking behavior and have a history of fewer previous low-lethal suicide attempts. ${ }^{33}$ However, people who attempt suicide by high-lethal methods may get more attention and hospital care, compared to their counterparts who attempt suicide by low-lethal methods. The risk of suicide reattempt in individuals with high-lethal suicide attempts may be reduced under medical intervention. In contrast, people who attempt suicide by low-lethal methods might have a higher probability of parasuicide and suicide communication, or suffer from personality disorders. ${ }^{34}$ Although we found that those attempting suicide by low-lethal methods were more likely to make a subsequent attempt, whether the risk of repeated suicide attempts is associated with mortality rate warrants further investigation.

In the study sample, females were two times more likely to attempt suicide than males, and males tended to use more lethal methods than females. This finding is generally consistent with current knowledge. ${ }^{24,35}$ However, sex only showed a borderline significant effect of predicting subsequent suicide attempts in adjusted Cox proportional hazard modeling. In most studies, male sex has been associated with higher mortality rates due to suicide, ${ }^{3,36}$ while female sex has been linked to a higher incidence of repeat suicide attempts. ${ }^{18} \mathrm{~A}$ discrepancy regarding the rate of repeat suicide attempts between sexes exists among previous international studies. ${ }^{22,37}$ Social environment and cultural differences might be important factors accounting for the conflicting results. ${ }^{38,39}$ Nevertheless, the findings in this study suggest that suicide method may play a more significant role than sex for predicting the incidence of repeated attempts.
In this study, being middle-aged - between 35 and 49 years - was an independent predictor of subsequent suicide attempts, while being middle- to old-aged ( $>50$ years) was an independent factor of changing suicide method. Numerous researchers have reported that old age is an independent factor of suicide death, ${ }^{20,22}$ whereas young and middle-aged (20-49 years) people were reported to be less likely to choose a highly lethal method, which may be associated with a higher rate of repeat suicide attempts. ${ }^{18,40}$ Taken together with our findings, the literature shows that elderly individuals might have stronger suicidal intent and tend to try different suicidal methods for the next suicide attempt. On the contrary, middle-aged individuals are more likely to make a repeated suicide attempt; however, they consistently use low-lethal suicide methods. Although high rates of repeated suicide attempts do not necessarily represent high suicide mortality, clinicians should remain cautious when evaluating groups with multiple suicide attempts according to the association of eventual suicide death. ${ }^{41}$ In addition, it is noteworthy that the rate of suicide reattempts in adolescents with self-harm could be as high as $44 \%$ during an 8 - to 10-year follow-up. ${ }^{16}$ In our study population, $113(5.5 \%)$ individuals were younger than 20 years, and we found the rate of suicide reattempts in young subjects ( $<20$ years) was not significantly different to any other age groups (data not shown). However, the sample size and duration of followup were limited in this study, and further investigations are needed to elucidate the risk of suicide attempt repetition in young population $(<20$ years $)$.

Moreover, we found that most people who used low-lethal methods stayed in the same lethality level of suicide method in their second attempt, whereas those using high-lethal methods were more likely to change suicide method in their second attempt. Nishimura et $\mathrm{al}^{25}$ suggested that, although many people who attempt suicide tend to choose the same method in their next attempt, they may change the suicide method to a different lethal level and, thus, be more likely to complete suicide. Therefore, suicide survivors switching methods during the next attempt may be indicating a strong intent to die, so try another method to ensure completed suicide. However, individuals' subjective reasons for switching suicide method are difficult to ascertain from the surveillance database of our study. A number of the individuals who used high-lethal methods during their index attempt changed the method to a low-lethal one in subsequent attempts. This database was designed to choose survivors of an index suicide attempt, which may cause selection bias by excluding people who died from the index attempt. Hence, the population in 
this study might have a relatively weak intent to die, and this may account for the results of this study.

There are several limitations in this study. First, the index suicide attempt represents the first suicide act detected during the study period, but is not necessarily the first attempt in that individual's lifetime. Therefore, further clarification is required regarding whether the method of the first suicide attempt in a person's life predicts the pattern of a subsequent suicide attempt. Second, the lack of information about other important risk factors of suicide, including family history and psychiatric diagnoses of anxiety or mood disorders, personality disorders, psychosis, and alcohol or other substance use disorders, made it difficult to further analyze the association among those parameters and the manner of repeat suicide attempts. In addition, the suicide methods defined in this study only relied on ICD-9-CM coding, and a person's actual intention to die when attempting suicide was unknown. Third, because we lacked information on suicide mortality, we were unable to determine whether subsequent suicide attempts were eventually completed. A case-linkage study is warranted to elucidate this issue. Fourth, the data for the index suicide attempt were collected over 5 years (2006 to 2010) and participants were tracked until the end of 2011 to ensure that all participants were followed-up for at least 1 year after their index attempt. However, the time of follow-up was unequal between participants (from 1 to 6 years), and the estimation might be biased by the unequal time of observation. Finally, the data were collected from one community with a high suicide rate. Therefore, the results may not be generalizable to other populations.

\section{Conclusion}

This study showed that lethality level of initial method of suicide seems to be an independent predictor of subsequent suicide attempts and changing suicide method. This may provide a clue to clinicians concerning groups at high risk of repeated suicide attempts. However, further investigation is needed to clarify whether high risk of repeated suicide attempts is associated with high suicide mortality rates.

\section{Acknowledgments}

The authors express their deepest gratitude to the Department of Health, Keelung City Government, for providing the suicide data. This study was supported by the Chang Gung Memorial Hospital Research Project (CZRPG290021).

\section{Author contributions}

$\mathrm{YCH}$ participated in interpreting data, reviewing references, and drafting the manuscript. YWW, CKC, and LJW participated in the design of study. LJW executed the statistical analysis and drafted and revised the manuscript. All authors read and approved the final manuscript and contributed to the drafting and revising of the paper.

\section{Disclosure}

The authors report no conflicts of interest in this work.

\section{References}

1. Hawton K, van Heeringen K. Suicide. Lancet. 2009;373(9672): 1372-1381.

2. Public Health Action for the Prevention of Suicide: A framework. Geneva: World Health Organization; 2012. Available from: http://apps who.int/iris/bitstream/10665/75166/1/9789241503570_eng.pdf?ua=1. Accessed 11 June, 2013.

3. Chen VC, Tan HK, Chen CY, et al. Mortality and suicide after self-harm: community cohort study in Taiwan. Br J Psychiatry. 2011;198(1):31-36.

4. Lin JJ, Lu TH. Suicide mortality trends by sex, age and method in Taiwan, 1971-2005. BMC Public Health. 2008;8:6.

5. Chung KH, Lee HC, Kao S, Lin HC. Urbanicity and methods of suicide: a nationwide population-based study. J Urban Health. 2008;85(1):136-145.

6. Beghi M, Rosenbaum JF, Cerri C, Cornaggia CM. Risk factors for fatal and nonfatal repetition of suicide attempts: a literature review. Neuropsychiatr Dis Treat. 2013;9:1725-1736.

7. Cullberg J, Wasserman D, Stefansson CG. Who commits suicide after a suicide attempt? An 8 to 10 year follow up in a suburban catchment area. Acta Psychiatr Scand. 1988;77(5):598-603.

8. Rudd MD, Joiner T, Rajab MH. Relationships among suicide ideators, attempters, and multiple attempters in a young-adult sample. JAbnorm Psychol. 1996;105(4):541-550.

9. Cedereke M, Ojehagen A. Prediction of repeated parasuicide after 1-12 months. Eur Psychiatry. 2005;20(2):101-109.

10. Sakinofsky I. Repetition of suicidal behaviour. In: Hawton K, Heeringen KV, editors. The International Handbook of Suicide and Attempted Suicide. Chichester: John Wiley \& Sons Ltd; 2000:385-404.

11. Owens D, Horrocks J, House A. Fatal and non-fatal repetition of selfharm. Systematic review. Br J Psychiatry. 2002;181:193-199.

12. Bennewith O, Gunnell D, Peters T, Hawton K, House A. Variations in the hospital management of self harm in adults in England: observational study. BMJ. 2004;328(7448):1108-1109.

13. Reulbach U, Bleich S. Suicide risk after a suicide attempt. BMJ. 2008;337:a2512.

14. Kennelly B. The economic cost of suicide in Ireland. Crisis. 2007;28(2):89-94.

15. Brezo J, Paris J, Hébert M, Vitaro F, Tremblay R, Turecki G. Broad and narrow personality traits as markers of one-time and repeated suicide attempts: a population-based study. BMC Psychiatry. 2008;8:15.

16. Groholt B, Ekeberg O. Prognosis after adolescent suicide attempt: mental health, psychiatric treatment, and suicide attempts in a nine-year follow-up study. Suicide Life Threat Behav. 2009;39(2):125-136.

17. Monnin J, Thiemard E, Vandel P, et al. Sociodemographic and psychopathological risk factors in repeated suicide attempts: gender differences in a prospective study. J Affect Disord. 2012;136(1-2):35-43.

18. Scoliers G, Portzky G, van Heeringen K, Audenaert K. Sociodemographic and psychopathological risk factors for repetition of attempted suicide: a 5-year follow-up study. Arch Suicide Res. 2009;13(3):201-213. 
19. Bille-Brahe U, Jessen G. Repeated suicidal behavior: a two-year follow-up. Crisis. 1994;15(2):77-82.

20. Elnour AA, Harrison J. Lethality of suicide methods. Inj Prev. 2008; 14(1):39-45.

21. Runeson B, Tidemalm D, Dahlin M, Lichtenstein P, Langstrom N. Method of attempted suicide as predictor of subsequent successful suicide: national long term cohort study. BMJ. 2010;341:c3222.

22. Chen VC, Cheng AT, Tan HK, et al. A community-based study of case fatality proportion among those who carry out suicide acts. Soc Psychiatry Psychiatr Epidemiol. 2009;44(12):1005-1011.

23. Mann JJ, Apter A, Bertolote J, et al. Suicide prevention strategies: a systematic review. JAMA. 2005;294(16):2064-2074.

24. De Leo D, Milner A, Fleischmann A, et al. The WHO START study: suicidal behaviors across different areas of the world. Crisis. 2013;34(3):156-163.

25. Nishimura A, Shioiri T, Nushida H, et al. Changes in choice of method and lethality between last attempted and completed suicides: how did suicide attempters carry out their desire? Leg Med (Tokyo). 1999;1(3): $150-158$.

26. Lee CY, Wu YW, Chen CK, Wang LJ. The rate of fatality and demographic characteristics associated with various suicide methods: a community-based study in Northern Taiwan. Crisis. In press 2014.

27. Beautrais AL. Further suicidal behavior among medically serious suicide attempters. Suicide Life Threat Behav. 2004;34(1):1-11.

28. Cooper J, Kapur N, Webb R, et al. Suicide after deliberate self-harm: a 4-year cohort study. Am J Psychiatry. 2005;162(2):297-303.

29. Corcoran P, Keeley HS, O'Sullivan M, Perry IJ. The incidence and repetition of attempted suicide in Ireland. Eur J Public Health. 2004;14(1):19-23.

30. Owens D, Wood C, Greenwood DC, Hughes T, Dennis M. Mortality and suicide after non-fatal self-poisoning: 16-year outcome study. Br J Psychiatry. 2005; 187:470-475.
31. Suominen K, Isometsä E, Suokas J, Haukka J, Achte K, Lönnqvist J. Completed suicide after a suicide attempt: a 37-year follow-up study. Am J Psychiatry. 2004;161(3):562-563.

32. Silverman MM, Berman AL, Sanddal ND, O'carroll PW, Joiner TE. Rebuilding the tower of Babel: a revised nomenclature for the study of suicide and suicidal behaviors. Part 2: suicide-related ideations, communications, and behaviors. Suicide Life Threat Behav. 2007;37(3): 264-277.

33. Horesh N, Levi Y, Apter A. Medically serious versus non-serious suicide attempts: relationships of lethality and intent to clinical and interpersonal characteristics. J Affect Disord. 2012;136(3):286-293.

34. Chesin MS, Jeglic EL, Stanley B. Pathways to high-lethality suicide attempts in individuals with borderline personality disorder. Arch Suicide Res. 2010;14(4):342-362.

35. Callanan VJ, Davis MS. Gender differences in suicide methods. Soc Psychiatry Psychiatr Epidemiol. 2012;47(6):857-869.

36. Beautrais AL. Suicide and serious suicide attempts in youth: a multiplegroup comparison study. Am J Psychiatry. 2003;160(6):1093-1099.

37. Beautrais AL. Subsequent mortality in medically serious suicide attempts: a 5 year follow-up. Aust N Z J Psychiatry. 2003;37(5):595-599.

38. Wang AG, Nielsen B, Bille-Brahe U, Hansen W, Kolmos L. Attempted suicide in Denmark. III. Assessment of repeated suicidal behaviour. Acta Psychiatr Scand. 1985;72(4):389-394.

39. Canetto SS, Sakinofsky I. The gender paradox in suicide. Suicide Life Threat Behav. 1998;28(1):1-23.

40. Chen VC, Tan HK, Cheng AT, et al. Non-fatal repetition of self-harm: population-based prospective cohort study in Taiwan. Br J Psychiatry. 2010;196(1):31-35.

41. Reid WH. Prognosis after suicide attempt: standard of care and the consequences of not meeting it. J Psychiatr Pract. 2009;15(2):141-144.
Neuropsychiatric Disease and Treatment

\section{Publish your work in this journal}

Neuropsychiatric Disease and Treatment is an international, peerreviewed journal of clinical therapeutics and pharmacology focusing on concise rapid reporting of clinical or pre-clinical studies on a range of neuropsychiatric and neurological disorders. This journal is indexed on PubMed Central, the 'PsycINFO' database and CAS.

\section{Dovepress}

The manuscript management system is completely online and includes a very quick and fair peer-review system, which is all easy to use. Visit http://www.dovepress.com/testimonials.php to read real quotes from published authors. 